\title{
Mission and Teacher Identity: A case for relationships
}

\begin{abstract}
Eight Catholic school communities across Australia nominated teacher identity characteristics aligned with an understanding of Catholic school mission from a local community perspective. A data mining process (Leximancer, 2017) of the collated narratives from focus groups $(n=73)$ highlighted the mission concept, School, with a frequency of 295 appearances. An Interpretative Phenomenological Analysis (IPA) of the concept revealed characteristics of tradition, integration and participation and characterized their essence as 'a shared sacred mission'. Participant utterances that referenced teacher characteristics and frequencies within the narrative focused on: Community (38), Faith (13), and Life (9). Community utterances identified teacher 'connections with students,' 'staff relationships,' 'associations with the broader community,' and 'involvement in the life of the school.' Faith was expressed in teacher 'leadership,' 'Gospel values,' 'spiritual growth,' 'experience of church and connection with the charism of the Religious Institute.' Life involved teachers advancing student 'welfare,' 'service,' 'tradition,' and 'advocacy.' Overall, teacher identity characteristics integral to mission were discussed as Relationship Agency, Equity and Authenticity. Relational Agency entailed facilitation of student capabilities; Relationship Equity enacted social justice values of inclusion and respect; and Relationship Authenticity advanced and witnessed a foundational meaning system aligned with Catholic school tradition. The implications of the findings identified a case for relationships as being pertinent to mission for all teachers in Catholic schools, but teachers of Religious Education in particular.
\end{abstract}

Keywords: Catholic school identity, teacher identity, school mission, relationships.

$\begin{array}{cc}\text { William Sultmann } & \text { Raymond Brown } \\ \text { La Salle Academy } & \text { Griffith University } \\ \text { Australian Catholic University } & \text { Gold Coast } \\ \text { Brisbane } & \text { Queensland } \\ \text { Queensland } & \text { ray.brown@griffith.edu.au } \\ \text { william.sultmann@acu.edu.au } & \end{array}$




\section{Introduction}

The identity characteristics of a teacher when aligned to school mission advance student engagement and learning (Convey, 2012). In this paper, the term 'teacher' encompasses the Australian Institute for Teaching and School Leadership (AITSL, 2014) understanding of teacher which includes knowing students and how they learn, knowing the content and how to teach it, planning and implementing teaching and learning, creating and maintaining supportive environments, assessing and reporting on learning, engaging in professional learning and engaging with colleagues and community. Notwithstanding, the significant impact other adults working in the school community can have on the growth and development of children and young people, is also recognised and potentially influenced by findings which serve to inform and advance adult to student relationships.

The importance of teacher identity and connection to quality learning is not new (MCEETYA, 2008). The work of Edwards (2005) challenges teachers to step beyond traditional approaches to teaching and to work with students to develop a form of 'relational agency.' That is, to help students develop the capacity to engage others in a manner that looks for multiple solutions to a problem by bringing to bear the 'sense-making' of the group and the resources that they draw upon. In a similar vein, the research of Boaler (2008) encourages teachers to work with students to develop 'relational equity.' That is, the capacity to value diversity and enact an ethic of care (Noddings, 2005), by actively listening to and respecting others in the teaching learning process. The further process for engaging students underpinned by beliefs and values, 'relationship authenticity', is manifested in school mission statements and evident in unique ways of nurturing successful learners, confident and creative individuals, and active and informed citizens (Ministerial Council on Education, Employment, Training and Youth Affairs, MCEETYA, 2008, p. 4).

Research on teacher identity in Catholic schools (Gleeson, Goldburg, O’Gorman \& O'Neill, 2018) reveals relationships centred in faith, community, and life to be central. Faith relationships connect students to church and to the world; community nurtures relationships between teachers and students; and life relationships foster the integrated formation of the whole person - socially, academically and religiously. The significance of these elements is illumined in Magisterium documents of the Conciliar and Post-Conciliar period (Hall, Sultmann \& Townend, 2019) in which the continuity of mission was found to reside in dimensions of Faith, Learning, Community and Formation. Faith was expressed in the school 
as being an ecclesial community centred in beliefs and values; Learning based on an understanding of the human person; Community as a place of engagement, inclusion and dialogue; and Formation as the educational experience which forms students, parents and wider community in terms of the integration of faith, life and culture. Notwithstanding the importance of these teacher identity characteristics, they are preferenced within the formal and universal literature of the Church and warrant validation within the 'world' of the school and classroom.

Teacher identity is argued to be difficult to investigate as it cannot simply be reduced to elements such as faith, community, life; or even agency and equity (Roth, 2007). In light of this, researchers have focused on one or two characteristics of 'identity' in order to explore, for example, teachers' emotional relationships with a subject discipline (Hodgen \& Askew, 2006), learner epistemologies (Solomon, 2007), the development of individual agency in problem solving (Stone \& Gutierrez, 2007), and the development of student identity in the classroom curriculum (Aschbacher, Li, \& Roth, 2010). However, while each of these studies has provided valuable insights into the characteristics of identity in educational and relationship specific contexts; the focus of this article explores the relationship that teacher identity has with the overall identity of the Catholic school, and in turn, the impact of this on student development. As such, 'teacher identity' is conceptualised as a relationship-forming process where teachers and students express and communicate ideas according to a shared set of norms and practices related to the mission, life and culture of the Catholic school.

Central to the identity of the teacher is the related notion of 'funds of identity.' This entails a sociocultural perspective in keeping with the concept of 'funds of knowledge'. It refers to historically developed and accumulated bodies of cultural knowledge that are essential to the functioning of a Catholic school (Belmonte \& Cranston, 2009). This modelling of identity follows the work of Esteban-Guitart and Moll (2014) and incorporates dispositions and values as well as knowledge and skills, is grounded in membership, and incorporates experiences in and out of Catholic school contexts. This modelling of identity was employed because it has important implications relating to the characteristics through which a teacher's identity is communicated to students and has the potential to challenge teachers to consider their identity impacted by external stimuli often channelled through a media dominated society (Nieto, 2007; Thomas, 2011). Moreover, it can reflect the essence of a Catholic school's identity in ways that align with traditions and history. In other words, understanding teacher identity through the lens of the sociocultural construct 'funds of knowledge' supports a response to the questions of what relationships towards students do teachers privilege, and how do these relationships 
relate to the mission, life and cultural dimensions of the Catholic school in its historical and contemporary context?

The process of analysis followed in this research is premised on Mikhail Bakhtin's notion of voice. Bakhtin (1986) formulated a theory of voice which emphasised the active, situated, and functional nature of speech as it is employed by various communities (for example teachers) within a society (for example a Catholic school). Taking the notion of 'utterance' rather than 'word meaning' as a basic unit of analysis, Bakhtin maintained that in dialogue with others, people give personal voice to utterances that are imbued with the meanings, intentions, and accents of past and present contexts of use (Bakhtin, 1981, p. 293). In this sense, Bakhtin's notion of utterance expands the basic unit of an analysis to encompass a broader range of contextual issues relating to a person's perspective, belief system, intention, and view of the world (Wertsch, 1990). In other words, from a Bakhtinian perspective, an utterance may be any form of spoken, written or non-verbal communication which is a link in a chain of communication. Within this chain of communication, the speaking personality of the author is inherently related to the voices of others (past or present) who may either agree, disagree, augment or otherwise respond to the utterances contained within it (Bakhtin, 1986).

\section{Method}

Focus group workshops were conducted within a national educational planning process to generate characteristics of Catholic school identity and teacher characteristics aligned with such perceptions. Workshops were undertaken with a representative sample of eight schools drawn from a pool of 36 schools oversighted by a Catholic Religious Institute. The schools selected were reflective of the diversity of the overall federation of schools and incorporated representation across dimensions of geography, student gender, size, location, and socioeconomic status. Each focus group discussion engaged seven to ten people $(n=73)$ and extended across a three to four-hour period. Participants typically included members of school leadership teams; school board nominees; the mission co-ordinator; staff representatives (teachers and support personnel); and parents. Each workshop was facilitated by an executive officer of the Religious Institute and recording of participant responses was performed by a local contact person. The format for each workshop was consistent and comprised elements of welcome, clarification of workshop purpose and process, an overview of the meaning of school identity, the significance of language, and the practice of reflection and discussion contribution from the personal experience of Catholic school culture and mission. 
The central focus of the workshop was to articulate mission characteristics of the school and identify processes, structures and behaviours ('school practices') which align to these characteristics. General questions were posed to facilitate reflection of school identity and aligned practices and included: 'Which practices, structures, processes, or events in the life and work of our school are intrinsic to identity? By intrinsic, we mean they help to define who your school is ...... another way of thinking about your school is what is it that we do that makes our school different and special?' Participant responses to these questions were recorded, collated and transcribed for analysis.

\section{Tools of Analysis}

Leximancer and Interpretative Phenomenological Analyses (IPA) were performed on the collated narrative from each focus group. Leximancer is a text-based research tool that analyses script and displays the extracted core concepts; that is, collections of words that occur throughout a transcript, as a 'concept map' showing the relationships of concepts to each other (Leximancer Manual, 2017). IPA aims to reveal the meaning contained in texts and transcripts through a process of interpretative engagement of the discourse (Smith, Jarman \& Osborn, 1999), which in turn offers a breadth of perspective to the 'voices' of participants (Larkin, Watts, \& Clifton, 2006). Phases of generating main ideas, synthesising through themes, and integrating overall data by an integrating principle are the processes typically applied within this discourse analysis method.

The process of data analysis entailed three stages. First, Identity concepts were identified from the overall pool of narrative responses; second, the most frequently occurring identity concept was examined in terms of the frequency and coding of utterances; and, third, each category of utterances was explored in terms of teacher identity characteristics integral to the mission of the Catholic school.

\section{Step 1. Nomination of Identity: concepts, themes and principles}

The dominant identity concept in the Leximancer analysis of the collated focus group text was that of 'School,' with 'Students,' 'Community' and 'People' being the next three most highly weighted associated elements within the discourse.

An IPA was conducted on these concepts and associated text passages. The concept of 'School' was fostered through expressions of tradition, integration and participation; 'Students' through individualisation, religious dimension, holistic outcomes and pastoral care; 'Community' 
through formation of a faith and model community; and 'People' through emphasis on the person and the pervasiveness of values. The overall principles which were aligned with the identity concepts and themes were: School - a shared sacred mission; Students - personal evangelisation for life; Community - being and building Christian community; and People authentic witness (see Sultmann \& Brown, 2011 for a full IPA analysis of these concepts).

\section{Step 2. Identity concept of 'school' and participant utterances}

The concept of school appeared 295 times within the collated narratives. In terms of direct teacher identity utterances, the concept was expressed 78 times with the overwhelming majority, 38, belonging to the category Community, 13 to the category Faith, and nine to the category Life, with 18 of the utterances falling outside of the category definitions, and mainly referring to demographic information such as the number of teachers in a school or to the profile of the community more generally.

\section{Step 3. Utterances and insights into teacher identity}

Community utterances and teacher identity

Within the category of Community, 24 utterances centered around teacher characteristics as facilitating student empowerment (the curriculum is vertically structured, to allow students to take responsibility for their learning); self-concept, self-belief, and self-control was significant (the development in individual initiative, self-reliance and self-motivation); promoting belonging and personal motivation (there is the sense of belonging and involvement); respect of difference, mentoring, and encouragement of social justice (inclusive of all - regardless of culture, academic ability, belief, gender, disability, socio-economic status). Also, within the cluster of utterances regarding 'community,' teacher identity was concerned with 'place,' 'curriculum,' and 'students at risk.' In terms of 'place,' relationships were viewed as revolving around working collegially (there is a single staffroom which promotes staff relationships); and, recognition of student demographics (youth come from 120 different suburbs). Overall, the school is represented as a place that has 'a positive orientation to students, ' promotes 'a culture of individual difference and acceptance,' that is 'inclusive of all,' and that 'is welcoming of all,' a place where 'students have a sense of achieving something and understanding their identity' and wish to 'stay in contact.'

Community and teacher identity characteristics in terms of 'curriculum', focused on 'the basics' (staff have time for the students and do the 'basic stuff' well ...), and engaging in 
outreach ('empowering staff to recognize students at risk'). However, the boundary between teacher and student was well defined and couched in terms that focused on practices, programs and traditions of the school (e.g., every student is important. All the structures of the school are focussed on promoting this reality. Discipline is based on right responsibilities and respect... discipline flows from the way we are in all our programmes... it is well documented, communicated with all and engaged with students effectively...).

Community utterances and teacher identity were connected to the 'broader community' in terms of 'history' (the story of the school demonstrates this), the 'work' of the school (the school works at the connectivity in school relationships through sports teams ...), 'building society' (building community is important for an inner city school as there is no local community), 'expectations' (the school is clear in its high expectations of students and parents and these are supported by the school community), and 'respect' (there is a great respect for the school by the graduating class). For 'community,' utterances connected to the 'life of the school' and teacher behaviours centred on the involvement of all staff (involvement of the school office staff in the life of the school is extensive and encouraged...), tradition (the traditions were retained and recognised by the school as authentically present now ...), integration (this encourages the sense that everyone is involved and supporting everything ...), and connection with people beyond the days of schooling (keeping the connections beyond school). Overall, for the category of community, participant utterances viewed teacher identity focused on what is and what 'should be' rather than on what 'could be' within the mission of the school.

Faith utterances and teacher identity

The category of faith and teacher identity was constructed around relationships that promote 'leadership,' 'Gospel values,' 'spiritual growth,' 'experience of church,' and 'the charism of the Religious Institute' in Catholic education.

Leadership, utterances centered around teacher characteristics related to the Religious Education program (the RE programme in Year 12 is focussed on leadership) and involvement with the life of the school (student leadership opportunities focus on making a contribution to the school). In terms of 'gospel values' and 'spiritual growth,' utterances referred to the activities of the school (Gospel values are reflected in the activity of the school), and the school's priorities (the personal and spiritual growth of each student is also of great importance to the school). Utterances related to 'the charism of the religious institute' 
highlighted the necessity to maintain the relevance of the Religious Institute to the life of the school (the school has functions that keep the connection with the religious order..), and in terms of the vocational nature of the work of the school (it inspires us to ... see our role in the school as a vocation).

Life utterances and teacher identity

Comments on life were constructed around teacher characteristics that focused on relationships that promoted 'student welfare' (we feed kids at the school before school starts), 'service' (leadership in the school is based on the Gospels "servant leadership"), 'tradition' (there is a 50-year-old tradition of a weekly working bee. It keeps happening because of the relationships formed at school ...), and 'advocacy' (students being seen around the city are advocates for the school ...). The overall utterances which linked school identity and teacher behaviour reflected the immediate life of the school and its continuing emphasis for the mission of the school to be carried into the community in support of the community.

\section{Discussion}

Teacher identity characteristics were established from commentary by a cross section of Catholic school communities on the identity of the Catholic school. The dominant identity concept of School was summarized and advanced through an integrating principle of 'a shared sacred mission' and manifested by teacher contributions to Community, Faith, and Life dimensions of the school. Community was characterised by teacher 'connections with students,' 'staff relationships,' 'associations with the broader community,' and 'involvement of staff in the life of the school'. Faith was evident through 'leadership,' 'Gospel values,' 'spiritual growth,' 'experience of church,' and charism of the Religious Institute.' Life was seen in the promotion of student 'welfare,' 'service,' 'tradition,' and 'advocacy.'

Catholic school teacher identity is argued to embrace the expectations of the profession, the vocation to teach, and teaching as ministry. Teaching is the professional response which carries the expectations of the profession, school and community; vocation is the call to teach in accordance with the expectations of the organisational entity within which it is carried out; and, teaching as ministry expresses vocation as sharing in the ministry of Christ within a Catholic Christian faith community (Sultmann, 2018). Within this view every staff member in a Catholic school is called to ministry as each contributes differentially, personally and communally, through witness, engagement and action in the religious education programme, the religious 
dimension to the curriculum, the religious life of the school, and the religious culture evidenced in structures, processes and systems.

The development of teacher identity in the contemporary Catholic school is said to incorporate an integration of faith, life and culture; engagement of the head, heart and hand; and, outcomes of a personal, strategic and ecclesial nature (Hall \& Sultmann, 2019). In short, formation is centred in relationships which accord with the mission of the school which is integral to life and living. A focus on relationships as key to teacher identity entails the activation of student voice as a process of empowerment within the educational experience; the provision of a service which is inclusive and equitable in its delivery; and, a service in ministry where the teacher, and all staff members, serve authentically the mission of the school.

\section{Relational Agency}

The provision of Student Voice articulated within Article 12 of the United Nations Convention on the Rights of the Child comprises four elements: space (the opportunity to express a view); voice (the facilitation of this view); audience (the community of learners listening to this voice); and influence (the voice is acted upon as might be appropriate). The declaration is a statement about student agency shaped by student engagement and responsibility. Relational agency (Edwards, 2005) draws from quality relationships with others (teachers, parents, students) within social and cultural tools (traditions and values) that assist in the mediation of agency. From this perspective, relational agency increases the pathways, solutions and options that facilitate student engagement and self-direction in the multicultural, complex and pluralistic nature of schooling.

The promotion of relational agency was evident in the responses of participants as they referred to the capacity of students to interact effectively and efficiently with others: "There is a benefit for the whole school in having junior students, for the opportunity it gives the older students for interaction and modelling." Another participant stated the advantages that staff and students experience when interacting through the school's discipline policy which empowered all: "Discipline is based on right responsibilities and respect... discipline flows from the way we are in all our programmes... it is well documented, communicated with all and engaged with students effectively so that they know the way things work. It embraces all relationships in the school: student to student, staff to staff, student to staff etc." 
Encouraging student agency in learning within the context of this study often required teachers to exercise high levels of flexibility. "The school day is busy and frenetic as any other school, but even when you are busy you allow yourself to be interrupted." This flexibility seems not only to apply to the content of learning activities: "Our innovative middle school is vertically structured, to allow students to take responsibility for their learning by encouraging them to make well informed choices, in interesting and challenging subjects, " but also to the processes and skills necessary to promote cohesion, a sense of pride and a sense of belonging in the school: "We work to enable the individual student to develop pride, belongingness and respect for others through participation throughout the period of the learning journey regardless of its length."

The promotion of student agency engages all. "Everything we do is integrated. There is a strong sense of integration of all these elements for all in the school. This encourages the sense that everyone is involved and supporting everything rather than just their specialist area. Staff induction and the experience of working alongside others who know the tradition and practice of the school in this matter, promotes this integration." However, these experiences do not work for all students requiring support from teachers that sometimes goes beyond the context of the school: "The school works hard to keep its students in education but if they do move on we work at supporting them in the transition and finding something for them."

\section{Relational Equity}

The data indicated that the work of teachers in Catholic schools engaged unpredictable and challenging situations that demanded flexibility and responsiveness to the individual and collective needs of all students. One participant in the workshops reported that this involves "the staff coming into the school picking it up as the culture. It's an attitude to the kids that says they are okay (even when they are difficult) there is a positive orientation to the students." Within the culture of the school, enacting relational equity means that "there is an awareness on the part of staff that the school is the major experience of 'Church' for most students and families." For teachers within these Catholic school contexts equity involves acknowledging the "strong social justice values underpinning the school - that make a difference to the person and then to the world."

Relational equity in the Catholic school context involves care for others within and outside the school community: "In our service to the wider community, we see our school as being a 
place of hope and encouragement in our world today." This understanding of relational equity acts as a reminder to staff and students of their need to share responsibility for the development of a "sense of belonging and involvement that results in the school being "accepted" throughout the community." This provides teachers with the means to communicate characteristics to the students that present Community as being "important in a big school to enable students to feel comfortable with their peers and the staff." Faith as being experienced through the "Gospel Values (that) are reflected in the activity of the school," and Life as "being a caring person" who is inspired "to share their diverse talents" and to "celebrate ... achievement across a range of gifts and abilities."

The interpretation of 'equity' presented in this article focuses on the situated nature of learning and the relationships between the participants in the study and the specific contexts in which they taught. It also aligns with the ways in which Edward's notion of 'relational agency' (2005) and Boaler's concept of 'relational equity' (2008), are used in research and is in accord with a notion of 'relationship authenticity' as expressed in the mission statements of the schools involved.

\section{Relational Authenticity}

The Catholic school aims to be a community of welcome, inclusion and uniqueness. Its mission is "fundamentally a synthesis of culture and faith, and a synthesis of faith and life: the first is reached by integrating all the different aspects of human knowledge through the subjects taught, in the light of the Gospel; the second in the growth of the virtues characteristic of the Christian" (Congregation for Catholic Education, 1977, para. 37).

The expression of relational authenticity is evident in the challenge: "the educator in Catholic schools must be, first and foremost, competent and qualified but, at the same time, someone who is rich in humanity and capable of being with young people in a style of pedagogy that helps promote their human and spiritual growth" (Pope Francis, 2014, para. 6). It engages all within the learning community in respectful dialogue and in support of a flourishing community intent on nurturing a civilisation of love (Congregation for Catholic Education, 2017). Teacher identity which manifests relational authenticity is centred in Christ as the foundation stone (Congregation for Catholic Education, 1977), and the universal goals of Church (Pope Benedict, 2005). It engages Scripture and Church Tradition and is manifested in teaching and witnessing 
to the person and message of Christ, being of service, forming a community centred in beliefs and values, and celebrating and sharing religious experience.

Catholic school communities embrace diversity and enact curriculum which is responsive, liberating and dynamic. Education for liberation is borne out in the right of every child to an education as enshrined in the Convention on the Rights of the Child (United Nations General Assembly, 1989) and articulated specifically in Article 29, (1d): "The preparation of the child for responsible life in a free society, in the spirit of understanding, peace, tolerance, equality of sexes, and friendship among all peoples, ethnic, national and religious groups and persons of indigenous origin." This is learning and teaching which aims to be informed, resilient, open and confident about the work of the Spirit. It is to encounter and engage the Spirit of Christ in the formal, informal, religious life, processes, structures and culture of the Catholic school. It is to vision horizons and enter pathways with trust, relationship and courage.

The utterances of participants around community, faith and life of the Catholic school reinforce the culture of the school as an authentic expression of the mission of the Church. The Catholic school engages a living encounter with a cultural heritage that is integral to the ministry of Church in service and communion within its local and wider community. The role of the educator as an agent of authenticity is one of walking with, listening to, challenging and modelling for young people the fullness of the Gospel as an attractive and relevant means for the development of self and community.

\section{Conclusion}

The relationship between teacher identity and Catholic school mission is evidenced in utterances about Community, Faith and Life dimensions of the school. This identity is argued to be evidenced in the promotion of relational agency, equity and authenticity with students. Relational agency is reflected in a culture of student participation and empowerment; Relational equity provides a basis for inclusion and processes of respect and dialogue in curriculum provision; and, Relationship authenticity establishes an overall foundation for teacher engagement manifested in the life and the culture of the Catholic school. When harmonised and held in balance, teacher identity centred in student agency, equity and authenticity, when congruent with mission characteristics, provides a powerful expression of education, summarised universally as: "to form and inform, to instruct and to empower the learner to know, to do, to live together and to be" (see Delors et. al. 1998, pages 86-99). 
The outcomes of a national colloquium on Religious Education (Hall \& Sultmann, 2019a) confirmed the interactive dimensions to teacher identity and emphasised the significance of formation, pedagogy, curriculum and partnerships to 'ways forward in Religious Education.' Notwithstanding, the focus on Religious Education, the conclusions were applicable to all staff in Catholic schools intent on being authentic to tradition while open and responsive to the profile and perspectives of its immediate community. Relational agency, equity and authenticity provide a context for this inclusive and dialogical approach to mission. 


\section{References}

Australian Institute for Teaching and School Leadership (2014). Website data. Retrieved from: https://www.aitsl.edu.au.

Aschbacher, P. R., Li, E., \& Roth, E. J. (2010). Is Science Me? High School Students' Identities, Participation and Aspirations in Science, Engineering, and Medicine. Journal of Research in Science Teaching, 47(5), 564-582.

Bakhtin, M. M. (1981). The dialogic imagination: Four essays. In C. Emerson \& M. Holquist (Ed., \& Trans.) Austin: University of Texas Press.

Bakhtin, M. M. (1986). Speech genres and other late essays (V. W. McGee, Trans.). Austin: University of Texas Press.

Belmonte, A., \& Cranston, N. (2009). The Religious Dimension of Lay Leadership in Catholic Schools: Preserving Catholic Culture in an Era of Change. Catholic Education: A Journal of Inquiry and Practice, 12(3), March 2009, 294-319.

Boaler, J. (2008). Promoting 'relational equity' and high mathematics achievement through an innovative mixed ability approach. British Educational Research Journal. 34(2), 167194.

Congregation for Catholic Education (1977). The Catholic School. Homebush, NSW: St Paul Publications.

Congregation for Catholic Education. (2017). Educating to fraternal humanism: Building a civilization of love 50 years after Populorum Progressio. Rome: Vatican City.

Convey, J. J. (2012). Perceptions of Catholic Identity: Views of Catholic School Administrators and Teachers, Catholic Education: A Journal of Inquiry and Practice, $16(1), 187-214$.

Delors, J., Al Mufti, I., Amagi, I., Carneiro, R., Chung, F., Geremek, V., ... Nanzhao, Z. (1998). Learning: The treasure within. Report to UNESCO of the International Commission on Education for the $21^{\text {st }}$ Century. Geneva: Unesco Publishing.

Edwards, A. (2005). Relational agency: Learning to be a resourceful practitioner. International Journal of Educational Research 43(3), 168-182. doi: 10.1016/j.ijer.2006.06.010.

Esteban-Guitart, M., \& Moll, L. C. (2014). Funds of identity: A new concept based on the funds of knowledge approach. Culture and Psychology, 20(1), 31-48. doi:10.1177/1354067X13515934

Gleeson, J., Goldburg, P., O’Gorman, J., \& O’Neill, M. (2018). Characteristics of Catholic schools as seen by teachers in the USA and Queensland, Australia. Summary report to Catholic schools in Queensland. Brisbane, Australian Catholic University.

Hall, D., \& Sultmann, W. F. (2019). Formation for mission: A systems model for advancing the formation of the religious educator within an Australian context. In M. T. Buchanan 
and A. M. Gellel, (Eds.). Global Perspectives on Catholic Religious Education Volume II: Learning and Leading in a Pluralist World. Netherlands: Springer Press.

Hall, D., \& Sultmann, W. (2019a). Ways forward in Religious Education. Religious Education Colloquium - Report on proceedings. La Salle Academy Publication Number 3: Sydney, Australian Catholic University.

Hall, D., Sultmann, W.F. \& Townend, G. (2019). Constants in context: An exploration of conciliar and post-conciliar documents on the Catholic school. Journal of Religious Education. Retrieved from DOI 10.1007/s40839-019-00074-6.

Hodgen, J., \& Askew, M. (2006). Relationships with/in primary mathematics: identity, emotion and professional development. Proceedings of the British Society for Research into Learning Mathematics, 26(2), 37-42.

Larkin, M., Watts, S. \& Clifton, E. (2006). Giving voice and making sense in interpretative phenomenological analysis. Qualitative Research in Psychology, 3: 102-120.

Leximancer Manual (2017). https://www.leximancer.com. Version 2.23.

Ministerial Council on Education, Employment, Training and Youth Affairs (MCEETYA) (2008). Melbourne declaration on educational goals for young Australians. Retrieved from:http://www.curriculum.edu.au/verve/_resources/National_Declaration_on_the_ Educational_Goals_for_Young_Australians.pdf on 23 July 2017.

Nieto, S. (2007). School reform and student learning: a multicultural perspective. In J. A. Banks, \& C. A. M. Banks (Eds.), Multicultural education: Issues and perspectives (6th ed.). (pp. 425e443) Hoboken, NJ: John Wiley and Sons Inc.

Noddings, N. (2005). Identifying and responding to needs in education. Cambridge Journal of Education, 35(2), 147-159.

Pope Benedict (2005). Love of God. Deus Caritas Est. Rome: Vatican City.

Pope Francis (2014). Address of Pope Francis to participants in the plenary session of the Congregation for Catholic Education. Retrieved from https://w2.vatican.va/content/francesco/en/speeches/ 2014/february.

Roth, W. M. (2007). Emotion at Work: A Contribution to Third-Generation Cultural-Historical Activity Theory. Mind, Culture, and Activity, 14(1-2), 40-63. doi:10.1080/10749030701307705

Smith, J. A., Jarman, M., \& Osborn, M. (1999). Doing Interpretative Phenomenological Analysis. In M. Murray and K. Chamberlain (Eds). Qualitative Health Psychology: Theories and Methods (pp. 218-239). London: Sage.

Solomon, Y. (2007). Experiencing mathematics classes: Ability grouping, gender and the selective development of participative identities. International Journal of Educational Research, 46(1), 8-19. doi:10.1016/j.ijer.2007.07.002 
Stone, L., \& Gutierrez, K. (2007). Problem articulation and the processes of assistance: An activity theoretic view of mediation in game play. International Journal of Educational Research, V46, n1-2, p. 43-56.

Sultmann, W. F. (2018). Cornerstone: Encountering the Spirit of Christ in the Catholic School. Melbourne: Coventry Press.

Sultmann, W. F., \& Brown, R. (2011). Modelling pillars of Catholic school identity: An Australian study. International Studies in Catholic Education, 3(1), 73-90.

Thomas, S. (2011). Teachers and public engagement: An argument for rethinking teacher professionalism to challenge deficit discourses in the public sphere. Discourse: Studies in the Cultural Politics of Education, 32, 371-382. doi:10.1080/01596306.2011.573253

United National General Assembly (1989). Convention of the rights of the child. Retrieved from: https:/www.un.org/documents/ga/res/44/a44r025.htm

Wertsch, J. V. (1990). Dialogue and dialogism in a socio-cultural approach to mind. In I. Markova and K. Foppa (Eds.), The Dynamics of Dialogue (pp.62-82). New York: Springer-Verlag. 